\title{
Application of Runge Kutta Time Marching Scheme for the Computation of Transonic Flows In Turbomachines
}

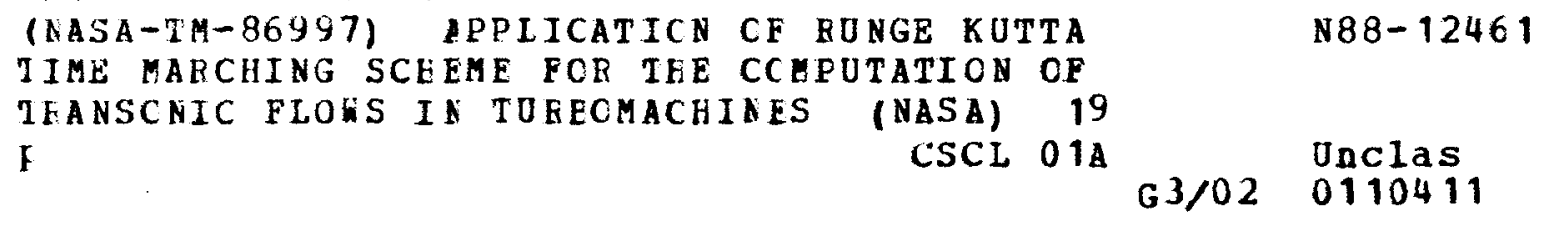

S.V. Subramanian and R. Bozzola AVCO-Lycoming Division

Stratford, Connecticut

Prepared for the

Twenty-first Joint Propulsion Conference cosponsored by the AIAA, SAE and ASME Monterey, California, July 8-10, 1985 


\title{
APPLICATION OF RUNGE KUTTA TIME MARCHING SCHEME FOR THE COMPUTATION OF
}

\section{TRANSONIC FLOWS IN TURBOMACHINES}

\author{
S.V. Subramanian' and R. Bozzola 2 \\ AVCO-Lycoming Division \\ $550 \mathrm{~S}$. Main Street \\ Stratford, Connecticut 06497
}

\begin{abstract}
SUMMARY
Numerical solutions of the unsteady Euler equations are obtained using the classical fourth order Runge Kutta time marching scheme. This method is fully explicit and is applied to the governing equations in the finite volume, conservation law form. In order to determine the efficiency of this scheme for solving turbomachinery flows, steady blade-to-blade solutions are obtained for compressor and turbine cascades under subsonic and transonic flow conditions. Computed results are compared with other numerical methods and cascade tunnel measurements. The present study also focuses on other important numerical aspects influencing the performance of the algorithm and the solution accuracy such as grid types, boundary conditions, and artificial viscosity. For this purpose, $\mathrm{H}, \mathrm{O}$, and $\mathrm{C}$ type computational grids as well as characteristic and extrapolation type boundary conditions are included in the solution procedure.
\end{abstract}

\section{INTRODUCTION}

A broad spectrum of flow conditions are encountered at various stages of a modern gas turbine engine operational cycle. These conditions are highly complex and are significantly diversified from one component to the other. Development of analytical tools closely representing the important flow features is a necessary step for efficient design, operation, and performance improvements. Due to the lack of computing resources and limitations of the existing analytical methods, no single study can hope to provide all the information and answers to the complete needs and satisfaction of the design engineer. Hence, development of numerical methods is customarily carried out in stages, ultimately hoping to produce a model representing the gas turbine flow field as realistically as possible.

The purpose of the present study is to develop a fast and accurate Euler cascade computer flow code that can be used for the design and performance improvements of critical gas turbine engine components such as compressors and turbines. Development of the solution procedure is based on the Jameson's fourth order Runge Kutta numerical integration scheme (ref. 1). This scheme has been successfully applied and shown to yield fast results with good accuracy for external aerodynamic flow problems. Other major advantages that

\footnotetext{
TSentor Research Engineer, Aerodynamic Design Group. Currentiy an Industry Visiting Scientist at NASA Lewis Research Center, Cleveland, Ohio 44135. Member AIAA. 2 Manager. Turbine Design and Development Group.
} 
prompted the authors to apply this method for internal turbomachinery flows are the simplicity and straightforward implementation procedure, independence of the steady-state solution on the time step taken and the vectorizable nature of the scheme.

The numerical results obtained in this study address several important issues related to the performance of the present method compared to the other schemes that exist in the literature for cascade flows (refs. 2 to 8). These issues include solution convergence, mass and total pressure conservation, grid types such as $H, O$, and $C$, boundary condition methods, and influence of flow geometry variation such as compressors and turbines.

\section{GOVERNING EQUATIONS AND NUMERICAL INTEGRATION SCHEME}

The Euler equations governing the two-dimensional inviscid flows can be written in the integral form as

$$
\frac{\partial}{\partial t} \iint_{\Delta R} U d x d y+\oint_{R}[F \cdot d y-G \cdot d x]=0
$$

where $\Delta R$ is the flow domain, $R$ is the flow boundary, $x$ and $y$ are the Cartesian coordinates. The vectors $U, F$ and $G$ in equation (1) are

$$
U=\left[\begin{array}{c}
\rho \\
\rho U \\
\rho v \\
\rho \mathrm{E}
\end{array}\right] F=\left[\begin{array}{l}
\rho U \\
\rho U^{2}+p \\
\rho U v \\
\rho U H
\end{array}\right] G=\left[\begin{array}{l}
\rho v \\
\rho U v \\
\rho v^{2}+p \\
\rho v H
\end{array}\right]
$$

Here, $p, u, v, p, E$, and $H$ are the density, velocity components in the $x$ and $y$ directions, pressure, total energy, and total enthalpy respectively. For a perfect gas

$$
E=\frac{p}{(r-1)_{p}}+\frac{1}{2}\left(u^{2}+v^{2}\right)
$$

and

$$
H=E+\frac{p}{\rho}
$$

where $Y$ is the specific heat ratio. Approximation to equation (1) leads to finite volume numerical method in conservation form.

\section{Runge Kutta Integration Scheme}

The flow domain is divided into a number of small finite volume (finite area in two dimensions) computational cells and the numerical approximation of equation (1) is applied to each cell separately. This procedure leads to a system of ordinary differential equations of the form 


$$
\frac{d}{d t}[U \cdot \Delta A]+\tilde{Q} \cdot U-\tilde{D} U=0
$$

which can be solved by any number of integration schemes. In this equation, $\Delta A$ is the cell area, $Q$ is the spatial differencing operator and $D(U)$ is the added artificial dissipative term to supress numerical instabilities in the region of very large flow variations. The exact form of equation (5) when applied to the $x$ momentum component for example, is (with the dissipative term omitted for simplicity)

$$
\frac{d}{d t}[\rho u \cdot \Delta A]+\sum_{k=1}^{4}\left(\tilde{Q}_{k} \rho u_{k}+\Delta y_{k} P_{k}\right)=0
$$

where the flux velocity $\widetilde{Q}_{k}$ is

$$
\tilde{Q}_{k}=\Delta y_{k} u_{k}-\Delta x_{k} v_{k}
$$

and the sum is over all four sides of the cell. In figure 1 the four sides of the cell $(1, j)$ are denoted by numbers one to four. The dependent flow variables such as $\rho$, $\rho u, \rho v$, etc. are cell centered and the values $(\rho U)_{k}$ across any side $k$ are average values on the two sides of the face.

For example,

$$
\begin{array}{r}
(\rho u)_{1}=\frac{1}{2}\left[(\rho u)_{1, j}+(\rho u)_{1, j-1}\right] \\
(\rho u)_{4}=\frac{1}{2}\left[(\rho u)_{1, j}+(\rho u)_{1+1, j}\right] \\
\Delta x_{1}=\left(x_{D}-x_{A}\right) \cdot \tilde{i} ; \Delta y_{4}=\left(y_{C}-y_{D}\right) \cdot \tilde{j}
\end{array}
$$

and so on.

Equation (5) is integrated using the modified four stage Runge Kutta scheme in which the dissipative terms are frozen at the values of the first stage. The values at the time level " $n$ " are then updated to the new time level " $n+l "$ in the following four stages:

$$
\begin{aligned}
& u^{(1)}=u^{n}-\frac{\Delta t}{\Delta A}\left[\tilde{Q} u^{n}-\tilde{D} u^{n}\right] \\
& u^{(2)}=u^{n}-\frac{\Delta t}{\Delta A}\left[\tilde{Q} u^{(1)}-\tilde{D} u^{n}\right] \\
& u^{(3)}=u^{n}-\frac{\Delta t}{\Delta A}\left[\tilde{Q} u^{(2)}-\tilde{D} u^{n}\right] \\
& u^{n+1}=u^{n}-\frac{\Delta t}{\Delta A}\left[\tilde{Q} u^{(3)}-\tilde{D} u^{n}\right]
\end{aligned}
$$

where $\Delta t$ is the local time marching step. The dissipative operator $\tilde{0}$ is a blend of second and fourth differences. The operator depends on the local 
flow behavior and is included in the exact fashion described by Jameson (ref. 1).

\section{BOUNDARY CONDITIONS}

With reference to figure 2, there are four types of boundaries that constitute the flow region and require special treatment. These are the inflow boundary $A H$, the outflow boundary $D E$, the solid-wall boundaries (BC and $G F$ ), and the periodic boundaries $A B, C D, H G$, and $F E$. The appropriate set of conditions for each of these boundaries is described below.

Inflow and outflow boundary conditions used in this study were the characteristic and extra-polation type. If the flow is subsonic there will be three incoming (right running) characteristics and one outgoing (left running) characteristic at the inflow while the opposite is true at the outflow boundary where there are three outgoing (right running) characteristics and one incoming (left running) characteristic. By the theory of characteristics, three conditions may therefore be specified at the inflow and one condition at the outflow (ref. 9). The remaining conditions are numerically determined by the solution of the differential equations. The three conditions specified at the inflow are the total pressure, total temperature, and the flow angle. The remaining condition is obtained by extrapolating the outgoing or upstream running Riemann invariant from the interior to the inlet. For extrapolation type, the static pressure is extrapolated from the interior cell to the inflow. For supersonic axial inflow, the inlet Mach number is also specified and held constant in addition to the three conditions mentioned above.

At the outflow boundary, the one physical condition specified is the static pressure corresponding to the desired exit Mach number. The three numerical conditions come from extrapolating the downstream running Riemann invarient, the $y$-velocity component $v$ and the total energy $E$. For supersonic axial outflow, the static exit pressure is also extrapolated from the interior point.

On the blade surface, the "zero flux" conditions are imposed. However, for estimating the contributions to the momentum equations due to the pressure terms, we need to evaluate the pressure on the blade surfaces. The normal pressure gradient at the boundary cell centers is determined by the same fashion described in reference 1. Extrapolation using the pressure gradient and the pressure at the cell center determines the pressure at the wall.

The periodicity is imposed by setting the flow variables in the cell centers that lie within the computational domain equal to the corresponding perlodic cells that lie outside the computational domain. For example (with reference to fig. 2), the unknown flow quantities in the control volumes that lie immediately above the periodic boundaries $A B$ and $C D$ are set equal to the corresponding cell values that 1 te immediately above the periodic boundaries $H G$ and $F E$ whose values are known from the interior point calculations. Additional detalls on the implementation of these boundary conditions can be found in references. 1 and 7 . 
Numerical solutions of the Euler equations using the Runge Kutta scheme described earlier were obtained for selected cascade test cases with widely varying geometrles and flow conditions. Results are presented and compared with solutions of other numerical methods and experimental data. Computational grids of different types were also used in the calculations to determine their influence on the solution accuracy.

The Mach number contours calculated for a transonic flow through a compressor cascade are 1 llustrated in figure 3 . The number of grid points used in the computations are 65 by 15 . The cascade geometry and the grids are shown in figure 2. The flow is subsonic at the inlet and accelerates to a peak Mach number of 1.246 on the blade suction side before shocking down to an extt Mach number of 0.67 . The computed surface Mach numbers agree very well with the predictions of other numerical methods. However, there are no experimental data avallable for this case.

Figure 4 depicts a high work turbine guide vane geometry (ref. 13) and the 80 by 17 computational grids used for obtaining a fully subsonic flow through the passage. The computed Mach number contours are shown in figure 5 . It is seen that the flow accelerates from an inflow Mach number of 0.11 to an exit value of 0.84 in a very short distance. The surface static pressure ratios obtained by the present method are shown in figure 6 along with avallable test data (ref. 13) an another code (ref. 14) using the two step explicit MacCormack numerical scheme. Considering the type and coarseness of the grids employed for this difficult test case, the present code yielded results with very good accuracy. Better accuracy can be achieved by refining and increasing the number of grid points in the flow field.

Next example is a flow through a NASA turbine stator rows shown in figure 7. The calculated critical surface Mach numbers are shown in figure 8 . The wind tunnel data (ref. 10) and the numerical results of another code (ref. 3) computed in house are also shown in this figure for comparison. The agreement of the present results with the test data as well as with the other method is very good. However, the poor agreement of the two numerical results with the test data near the leading edge is mainly due to the nature of the grid in this region. The numerical schemes treat the leading edge with "cusps" for solution convergence which is not present in the actual airfoil.

The treatment of leading and trailing edges with artificial cusps for numerical convenience is a common feature while computating flows with sheared "H" type grids as done in the previous test cases. This is particularly true for cascades with high incidence, large flow turning, and thick leading/ tralling edge profiles. Numerical results obtained with "H" grids are often inaccurate and misleading in these important flow regions. For improved accuracy, it is preferred that computations be performed on body fitted orthogonal or near orthogonal "C" or "O" type grids (ref. 11). To 1llustrate this point, the surface Mach numbers calculated on a "C" grid for the same test case of figure 7 are compared with the test data and this is shown in figure 9. It can be seen that the agreement is excellent and far improved near the leading and trailing edges compared to the "H" grid results.

Figure 10 shows an AVCO rotor blade and the "C" type computational mesh for which numerical solutions were obtained. This case was particularly chosen 
to test the ability of the present code to calculate transonic flows through turbine blade passages with high flow incidence, large turning, and thick blade profiles at the leading and tralling edges. The inlet flow angle is $55^{\circ}$, the inflow Mach number is 0.66 and the outflow Mach number is near transonic. The Mach number contours near the leading edge region is shown in figure 11 to illustrate the quality of results that can be obtained on a "C" grid with the present method. Computed surface Mach numbers are plotted in figure 12 along with the numerical results of reference 3 . The agreement between the two methods are very good except near the shock location where the present method predicts a peak value of 1.108 compared with 1.152 obtained by the Denton's code (ref. 3).

The VKI gas turbine rotor blade and the computational grids on which transonic flow solutions were obtained is pictured in figure 13 . Figure 14 compares the predictions of surface Mach numbers with test data obtained from two different cascade tunnels and two different exit flow conditions. The agreement between the present calculations and the two sets of test data is excellent especially for the case corresponding to exit Mach number of 1.19 .

\section{CONCLUSIONS}

A computer code for solving the Euler equations using the four stage Runge Kutta integration scheme has been developed for turbomachinery flow field calculation. The program has been successfully applied to predict blade-to-blade flows for many cascades with different geometries and flow conditions. Numerical results indicate that the present method can be applied to yield fast results with good accuracy for a wide variety of cascade configurations and flow conditions. The "c" type grids produce the best overall results for any particular test case from the stand point of accuracy, simplicity of implementation, and boundary condition treatments. The present code, which could be used in conjunction with any type of user opted computational grids, is simple, efficient, and accurate enough to be used for cost effective preliminary and advanced aerodynamic design studies.

\section{ACKNOWLEDGMENT}

This research and code development was conducted as part of AVCO Lycoming Independent Research and Development Program. The authors wish to thank Drs. Craig L. Streett, R.C. Swanson, and Manuel D. Salas, Theoretical Aerodynamics Branch, NASA Langley Research Center for sharing the technical information and experience they gained while implementing the numerical method of this study for computing external aerodynamic flows.

\section{REFERENCES}

1. Jameson, A., Schmidt, W. and Turke1, E., "Numerical Solutions of Euler Equations by Finite Volume Methods Using Runge-Kutta Time-Stepping Schemes," AIAA Paper 81-1259, June 1981.

2. Denton, J.D., "A Time Marching Method for Twoand Three-Dimensional Bladeto-Blade Flow," ARC R M-3775, 1975. 
3. Denton, J.D., "An Improved Time Marching Method for Turbomachinery Flow Calculation," ASME Paper 82-GT-239, Apr. 1982.

4. Delaney, R.A., "Time-Marching Analysis of Steady Transonic Flow in Turbomachinery Cascades Using the Hopscotch Method," ASME Paper 82-GT-152, June 1982.

5. Ni, R.-H., "A Multiple-Grid Scheme for Solving the Euler Equations," AIAA Journal, Vol 20, No. 11, Nov. 1982, pp. 1565-1571.

6. Thompkins, W.T., "Solution Procedures for Accurate Numerical Simulations of Flow in Turbomachinery Cascades," AIAA Paper 83-0257, Jan. 1983.

7. Subramanian, S.V. "Analysis of Time Marching Numerical Methods and Boundary Conditions for Turbomachinery Flow Computation," ASME Paper 84-GT-66, June 1984.

8. Chima, R.V., "Analysis of Inviscid and Viscous Flows in Cascades with an Explicit Multiple-Grid Algorithm," NASA TM-83636, 1984.

9. Chakravarthy, S.R., "Euler Equations - Implicit Schemes and Implicit Boundary Conditions," AIAA Paper 82-0228, Jan. 1982.

10. Whitney, W.J., et a1., "Cold-Air Investigation of a Turbine for HighTemperature-Engine Application," NASA TN-D 3751, Jan. 1967.

11. Sorenson, R.L., "A Computer Program to Generate Two-Dimensional Grids About Airfolls and Other Shapes by the Use of Poisson's Equation," NASA TM-81198, 1980.

12. Sieverding, C.H., "The Base Pressure Problem in Transonic Turbine Cascades," Transonic Flows in Axial Turbomachinery, Vol. 2, von Karman Institute for Fluid Dynamics, Rhode-Saint-Genese, Belgium, 1976.

13. Kopper, F.C., et al., "Energy Efficient Engine High Pressure Turbine Supersonic Cascade," NASA CR-165567, Nov. 1981.

14. Srivastra, B.N. and Bozzola, R., "Computations of Flow Fields in High Solidity and High Turning Angle Cascades Using Euler Equations, "AIAA Paper 85-1705, July 1985. 
- CELL NODES

(VALUES OF INDEPENDENT VARIABLES)

$\times$ CELL CENTER $S$

(VALUES OF DEPENDENT VARIABLES)

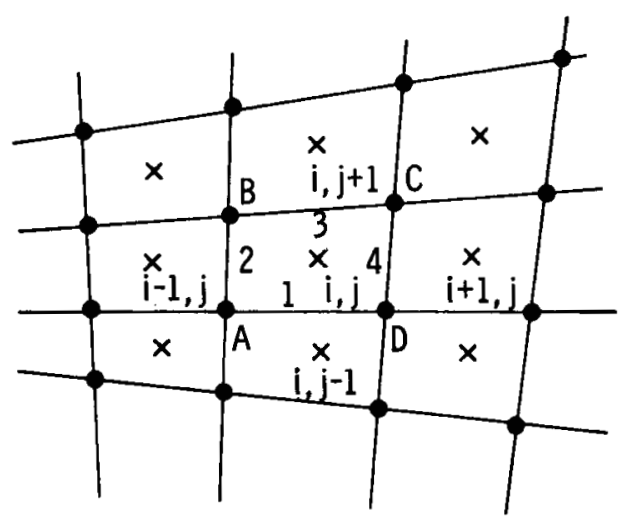

Figure 1. - Finite volume descretization.

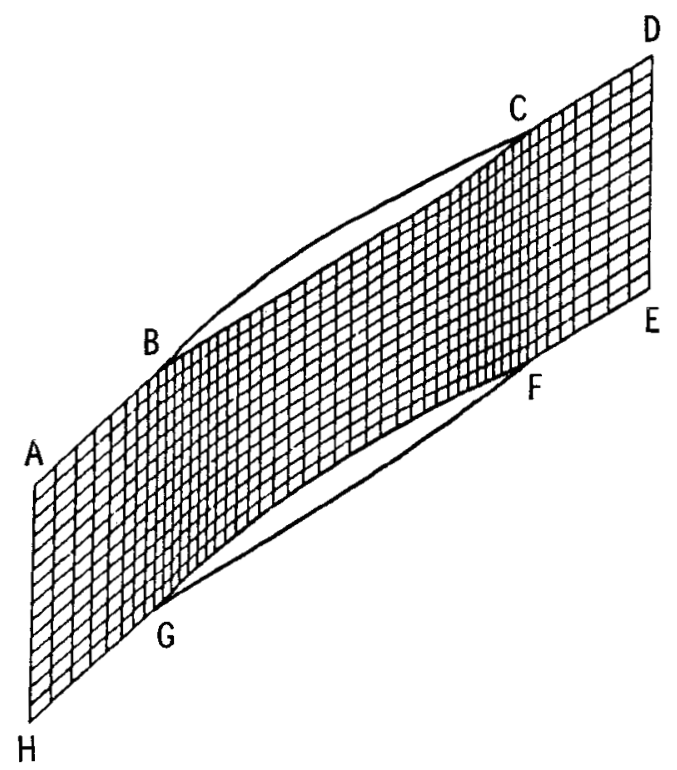

Figure 2. - Compressor cascade and computational grids. 


\section{ORIGINAL PAGE IS \\ OE POOR QUALITY}

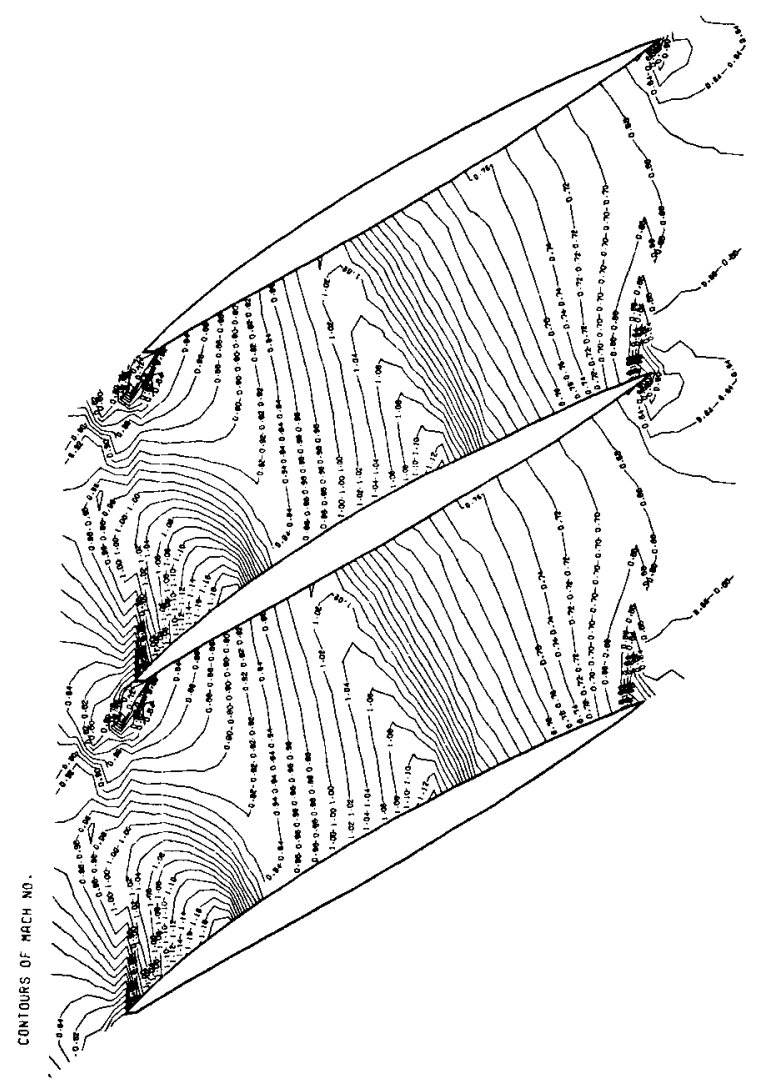

Figure 3. - Contour plots of Mach numbers. 


$$
1
$$




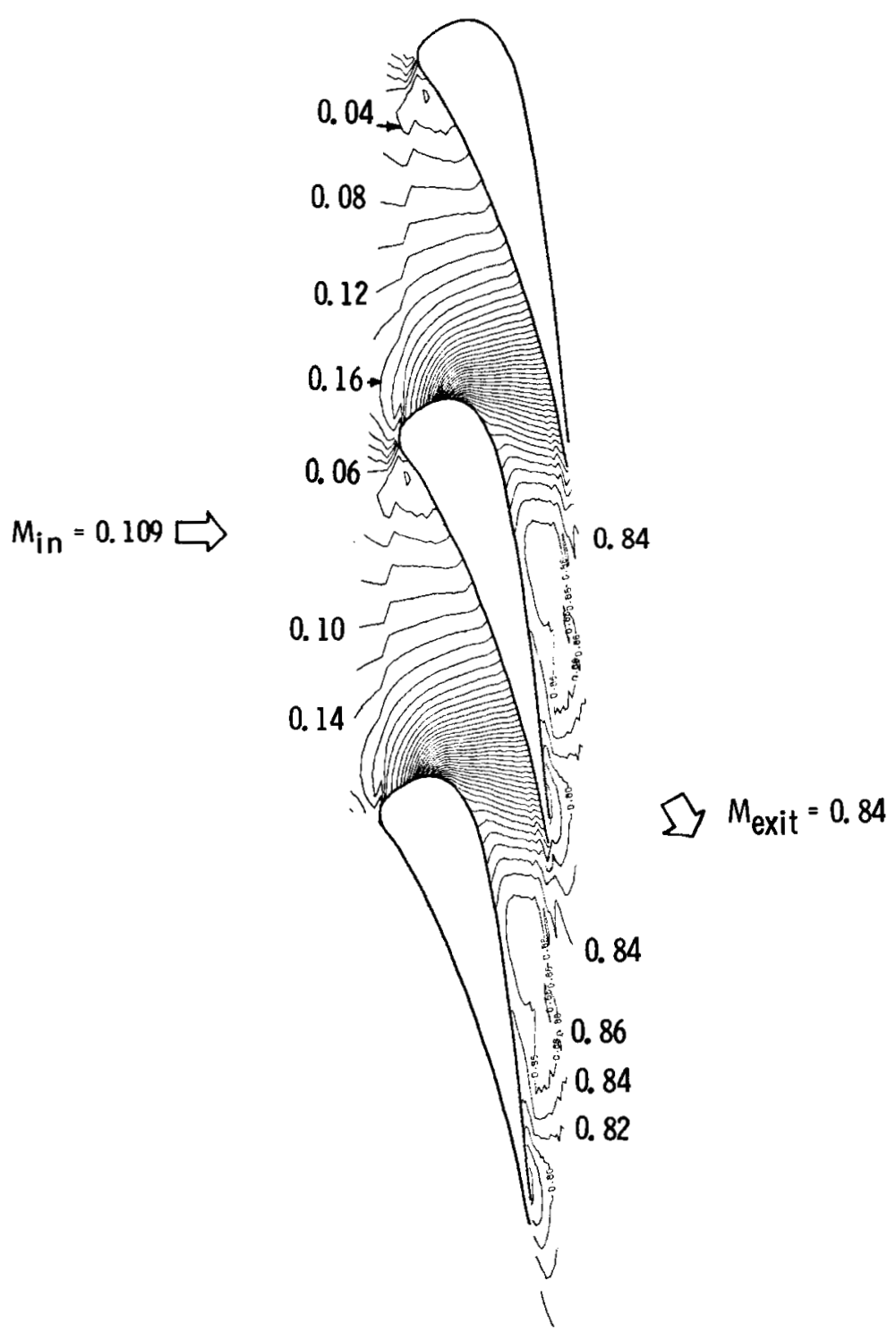

Figure 5. - Math number contours. 


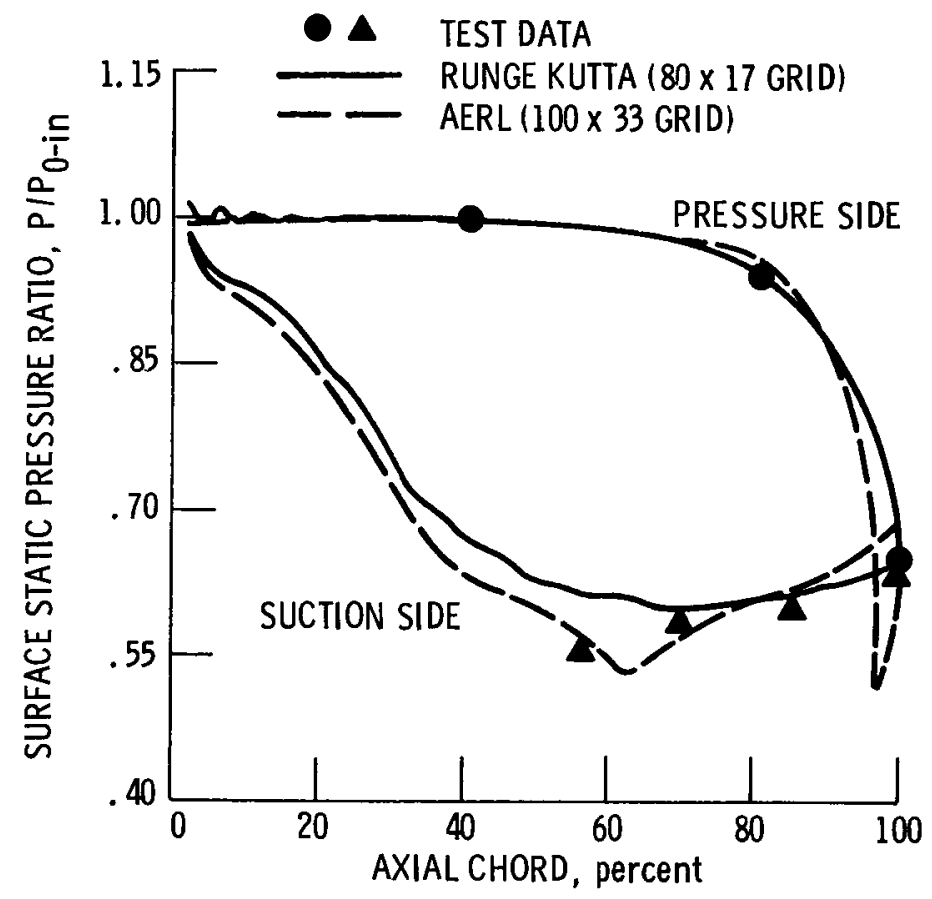

Figure 6. - Calculated surface static pressure variation.

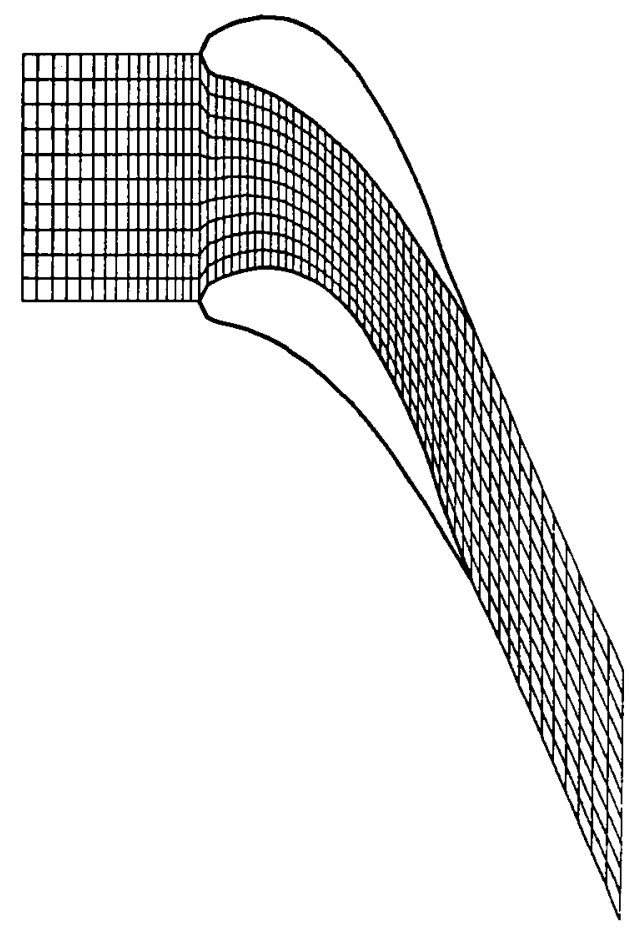

Figure 7. - NASA turbine stator geometry. 


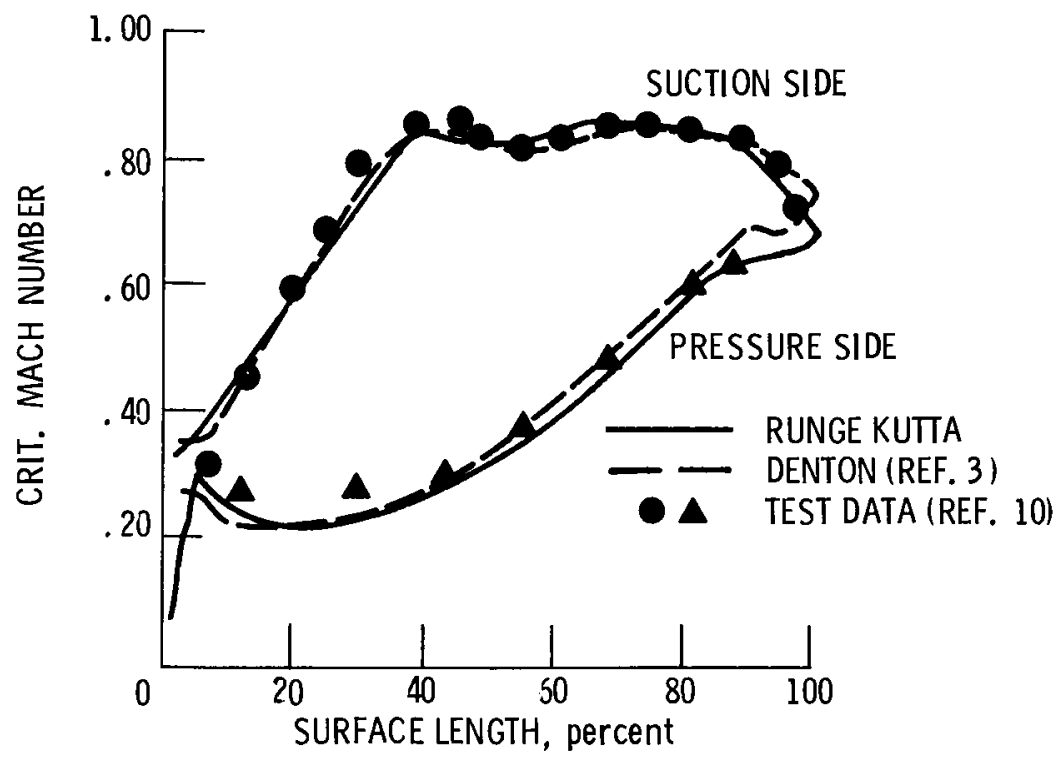

Figure 8. - Surface Mach number distribution.

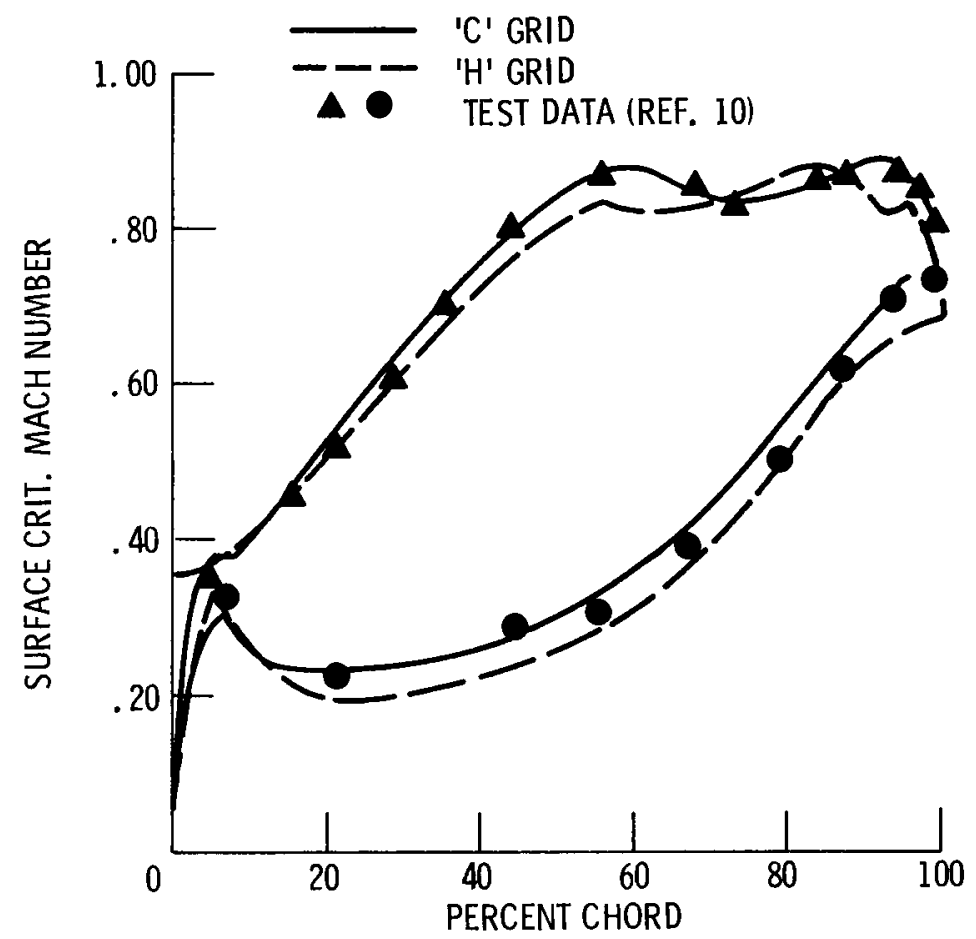

Figure 9. - Surface Mach number distribution. 


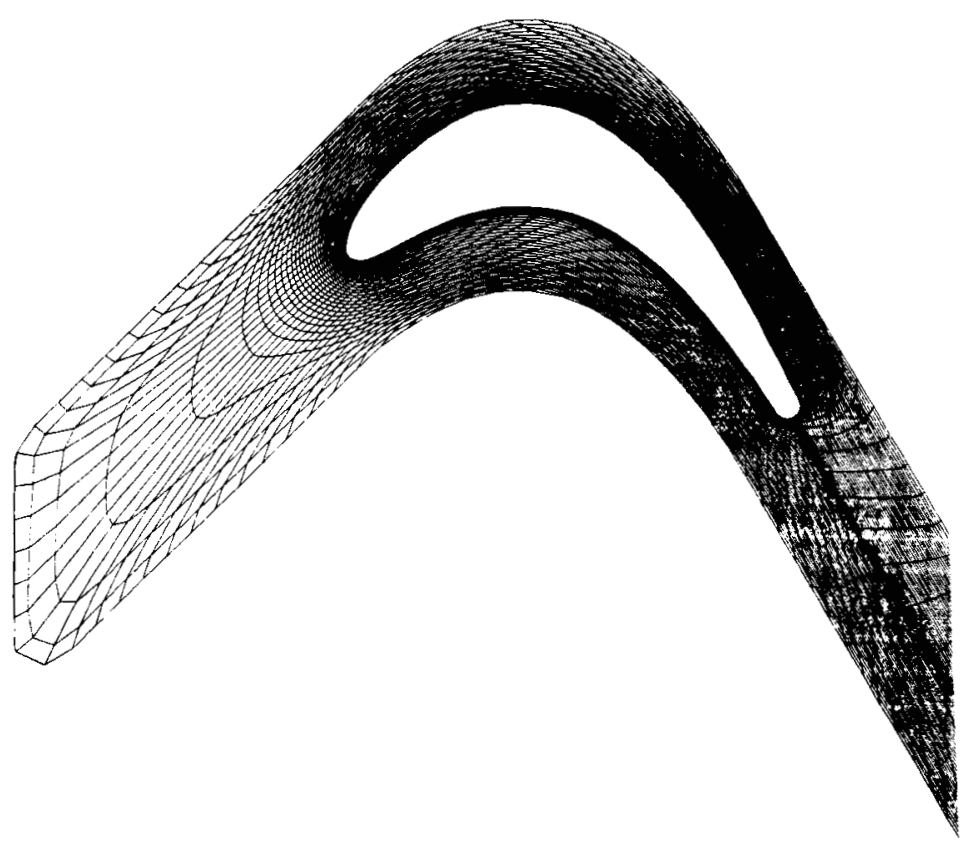

Figure 10. - AVCO turbine rotor geometry and computational ' $\mathrm{C}$ ' grids.

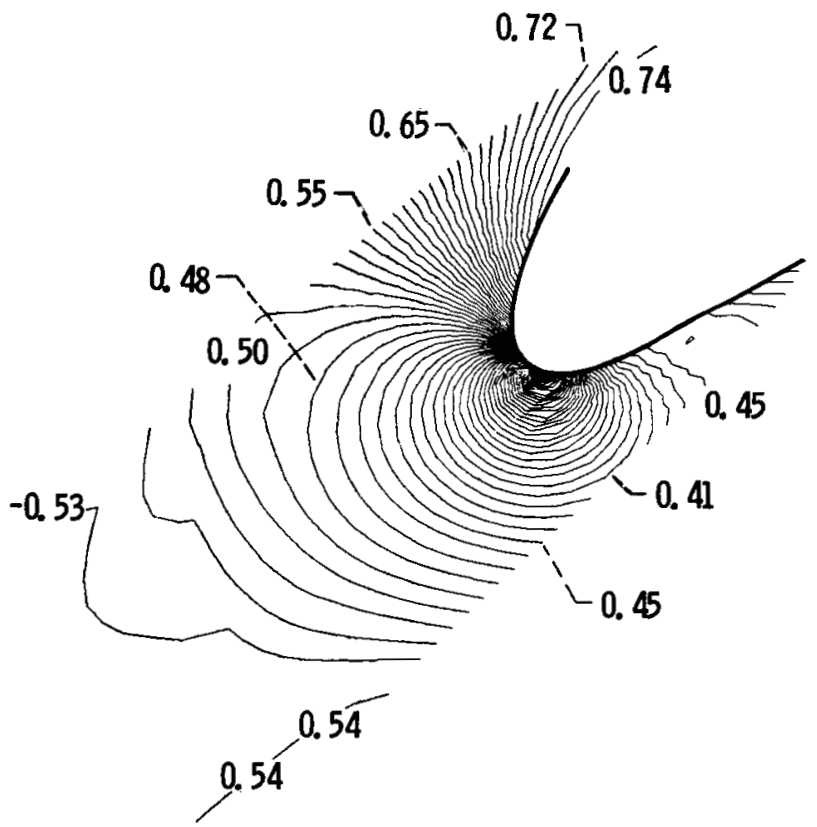

Figure 11. - Mach number contours near the leading edge of the cascade. 


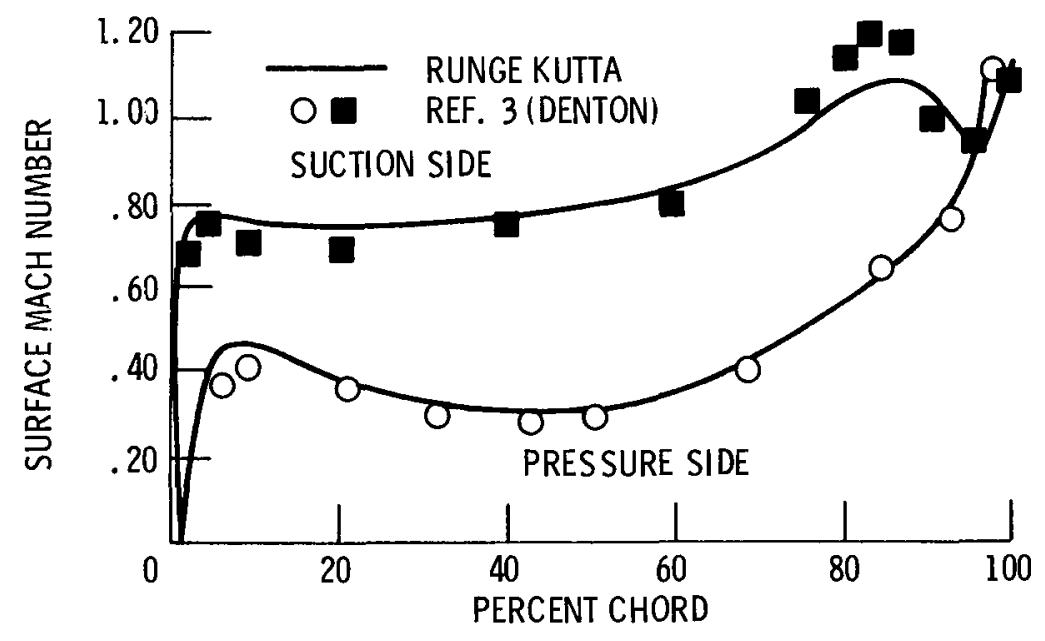

Figure 12. - Surface Mach number variation for AVCO cascade. 


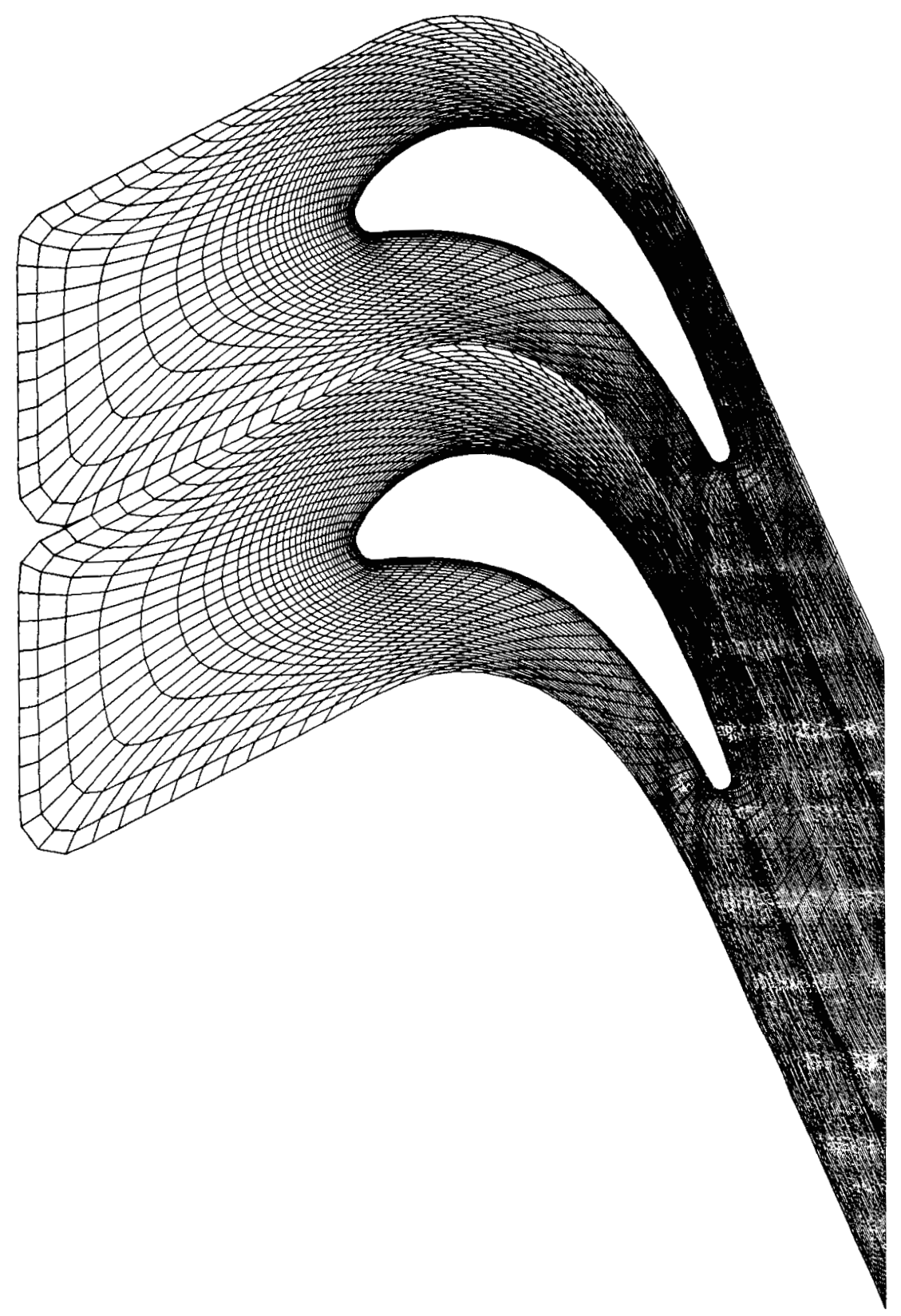

Figure 13. - VKI turbine cascade and computational ' $C$ ' grids. 


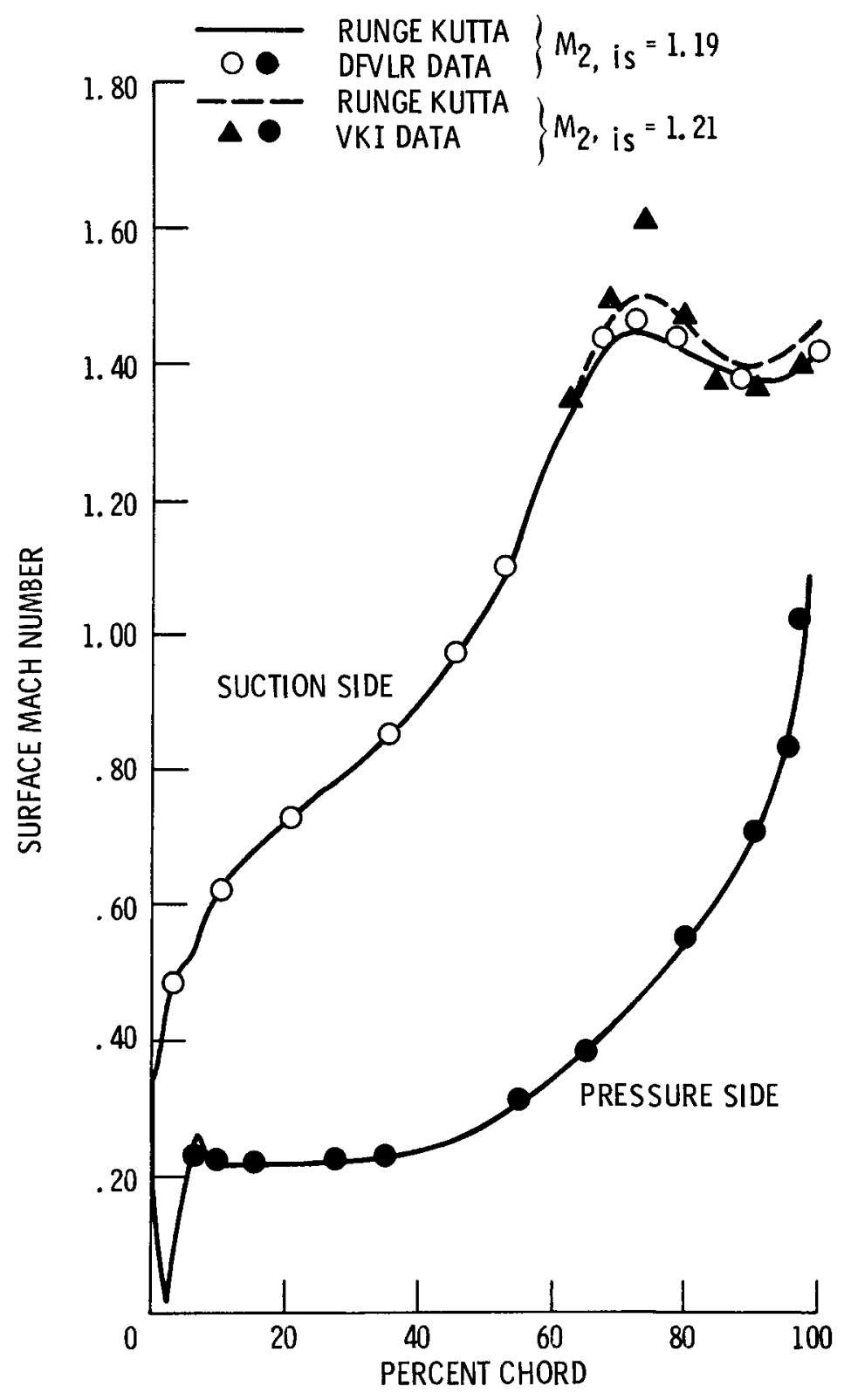

Figure 14. - Surface Mach number distribution. 


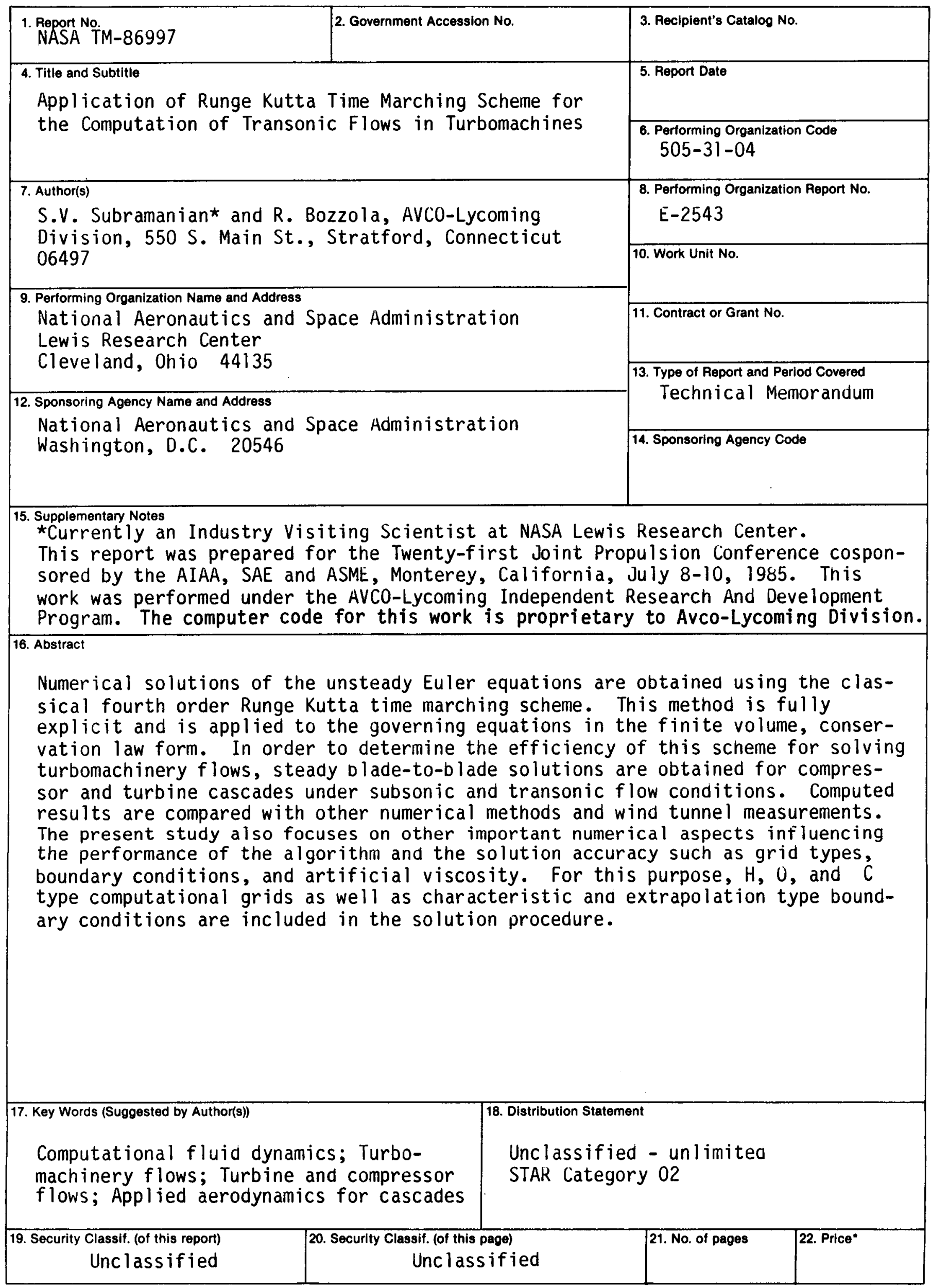

"For sale by the National Technical Information Service, Springfield, Virginia 22161 